\title{
Stability Container Closure System Terminology
}

National Cancer Institute

\section{Source}

National Cancer Institute. Stability Container Closure System Terminology. NCI

Thesaurus. Code C96080.

Terminology developed to support Closure Systems within the Stability Data Standards. 